\title{
Study on Basic Knowledge System of Industrial Design Engineering
}

\author{
Wang Chan \\ Jiangxi College Of Foreign Studies
}

\begin{abstract}
The science and technology development in twenty-first century impresses us like biological evolution, the blurred boundaries of disciplines, the newer technology derived from merging new technologies, changing the feature of traditional disciplines. Virtual reality technology is used in industrial design, making a more perfect combination of design activities and modern advanced manufacturing technology, bringing new reform opportunities for innovative industrial design of theory and methods. The paper constructs the basic knowledge system of industrial design engineering and discusses its main contents: the base of modeling material, the base of forming process, the base of surface technology and the base of digital technology. Finally, it concludes that designers should master the basic knowledge of industrial design engineering, communicate their design ideas in the design process of transmission of information and cultural values properly, rather than making noise in the visual and meaning transmission.
\end{abstract}

Keywords-Industrial design engineering; Industrial design; Network technology; Virtual manufacturing

\section{INTRODUCTION}

Master of engineering in industrial design engineering field is to adapt to the needs of national development of creative industries, and develop complex innovative talents with global vision of art and engineering in the arts, engineering, information interaction design fields. Master of Industrial Design Engineering has a certain artistic skills, and after training, they can master the appropriate engineering technology, with cross background of arts, engineering knowledge, showing more creativity, design and management capabilities. In the development and practice, these kind of cross-disciplinary talents are more helpful to produce more original results, favored by employers. The training of master of industrial design engineering and the master of engineering is different, and academic graduate is emphasized on learning of cutting-edge knowledge and design philosophy. Therefore, it is imperative to explore master's degree of industrial design engineering master education.

This paper presents theoretical model ICAID-VR system that the virtual reality technology applied in industrial design, and demonstrates the feasibility and far-reaching significance of the application of virtual reality technology in industrial design from two aspects, including the relationship of the evolution of longitudinal manufacturing model and engineering design, and the relationship between the development trend of lateral advanced manufacturing technology and industrial design.

\section{BASIC KNOWLEDGE SYSTEMS OF INDUSTRIAL DESIGN ENGINEERING}

Industrial design is a bridge between people and technology, which is to study the relationship between persons and things. From a practical perspective, industrial designers must be familiar with the engineering materials, processing method and the knowledge of computer science, information technology related to design objects and other aspects. In industrial design, the basic conditions forming product structure and achieving the function to use is reasonable selection of advanced modeling material and proper molding method and surface treatment processes to get satisfactory surface quality and good appearance. And industrial designers not only need to quickly and easily complete the design task, but must be familiar with CAID (computer aided industrial design). So industrial designers should have necessary mathematical knowledge, basic knowledge of mechanics and computer applications, but also must have knowledge of modeling material, forming process knowledge, surface knowledge and digital technology. The basic knowledge systems of industrial design engineering are shown in Fig . 1. 


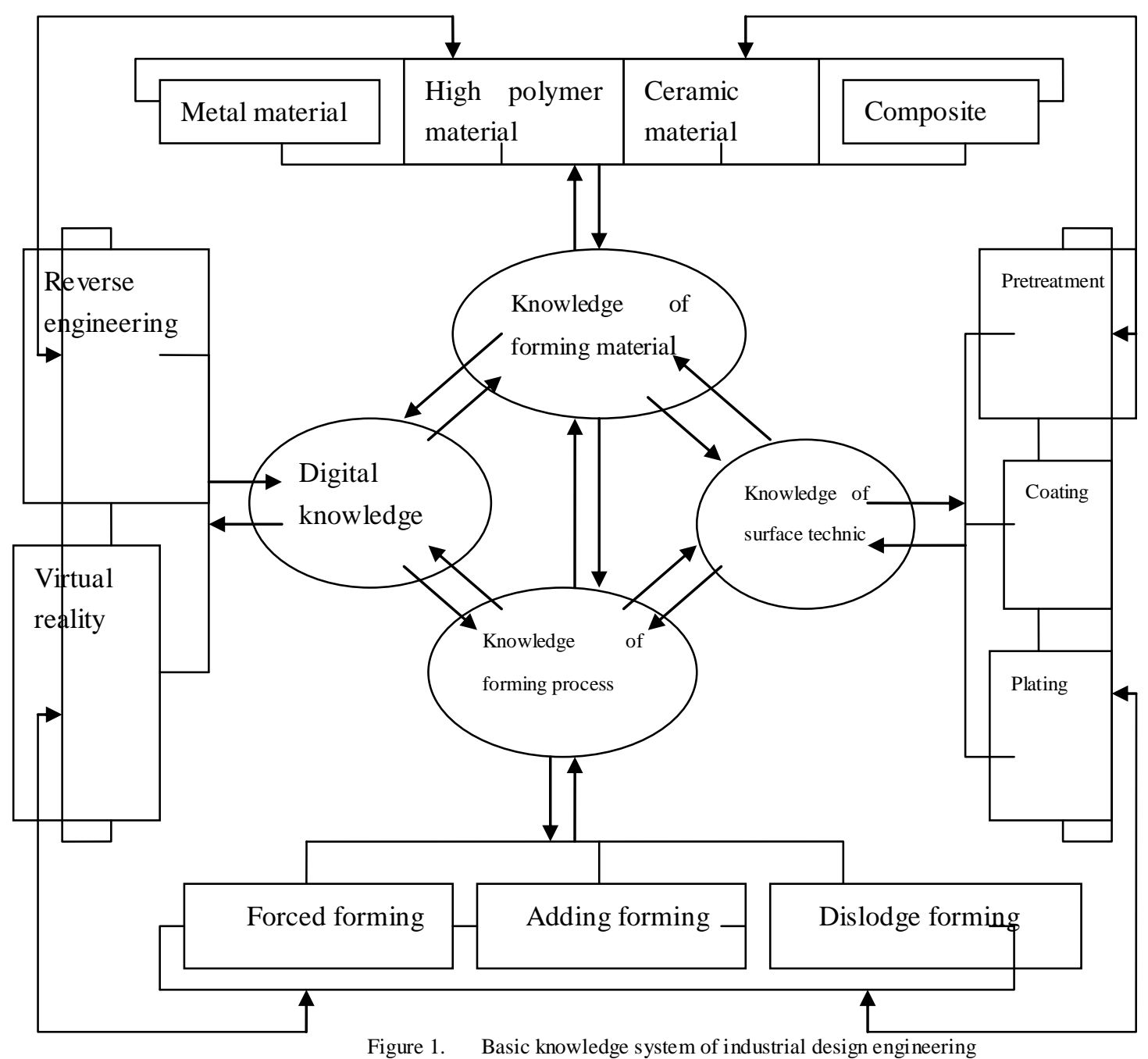

\section{PROBLEMS EXISTING INDUSTRIAL DESIGN ENGINEERING}

In recent years, full-time Master of industrial design engineering has been basically close academic graduate students. However, from the enrollment situation of on-job master in 2010 and 2011, most of the universities admitted to single-digit number. In 2011, the total number is only 528 , reflecting worse evaluation for the "occupation nature" and " practicality" of industrial design engineering. This shows that the practice of this postgraduate training links is weak or absent. Effective training mechanism is not really established. The main features include:

1. The occupational features of industrial design engineering master is not really understood and emphasized. It' s only managed based on the traditional academic master without independent training system. Industrial organizations and enterprises have failed to really participate in collaborative training, joint guidance and defense and other sectors. The innovation ability, practical ability and the ability to adapt to the positions are not enough, so the final phase of study has no direct function to obtain professional qualifications or promotion.
2. The pertinence of teaching model and curriculum is not strong, and most of them follow the academic training paradigm and are developed into the "abbreviated version" or "compact version" of academic graduate, " emphasizing theory and lighting practice" phenomenon is popular. The design practice courses lack of practice teaching and support facilities, mostly staying in the conceptual design paper, and a lot of courses ignore the actual requirements of enterprise engineering, inconsistent with the practice of their actual characteristics of the design project.

\section{INNOVATION DESIGN OF INDUSTRIAL DESIGN ENGINEERING}

ICAID-VR application for product design can achieve interaction and reversible result of the whole process from sketches - design sketch-structure chart-model. Using ICAID-VR technology can create online interactive virtual models used for design research; and customers can try this as virtual products, to get online statistical information, analysis of trends, greatly shortening product development time, reducing new product risk.

CAID-VR system can be divided into three parts, namely, ICAID-VR system, CAID system, PDM system. As shown in Fig .2. 


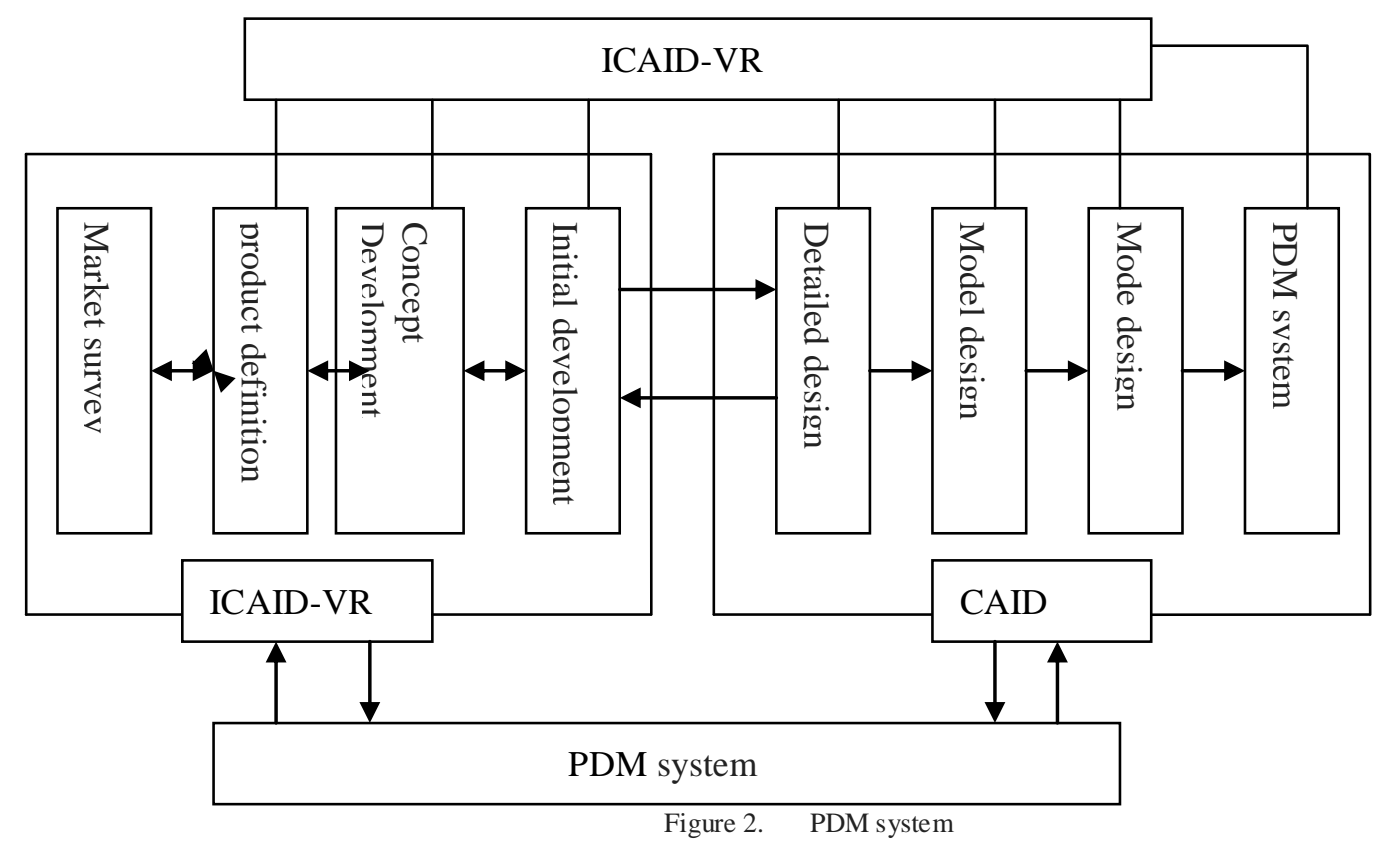

ICCID-VR system: the concept is different from ICCID-VR and it refers specifically to carrying out the preliminary design activities of ICAID-VR system by using VR technology, including market analysis, product requirements definition, conceptual design, preliminary design and other repeated processes in industrial design innovation stage. At this stage, use network technology and virtual reality technology to simplify the design process and reduce design time, convenient to modify at any time.

CAD (Computer Aided Industrial Design) system: specially refer to the detailed design, engineering design, model design, testing and evaluation and other design aspects in the later industrial design, which can output a set of relevant product data, implementating seamless connection with CAD / CAM / CAE, etc.

PDM (Product Data Management) system: product information and storage management systems. It provides network and data management services for the system, and the center of all parallel systems interaction information, including graphical information, structured information starting, text and language data, file information and other content.

\section{CONCLUSION}

The base of industrial design engineering are the main courses and required courses of industrial design major. Through courses teaching, students can understand the basic theory, basic knowledge and basic skills of industrial design engineering, laying a good foundation for learning subsequent engineering courses and the proper development of industrial design. This paper summarizes as follows:

(1) Industrial design engineering base is three kinds of basic knowledge for industrial designers;

(2) Molding material is the carrier of an industrial designer 's product.

(3) The molding process is the manufacture method of industrial designers.

(4) Surface technology is the means for industrial designers refining the products.

(5) The digital technology is an effective tool for industrial designers' design.

(6) Basic knowledge of modeling material, molding process, surface technology and digital technology constitute the basic knowledge systems of industrial design engineering, enabling the designer to correctly apply the principles of design semiotics, effectively conveying their design thought.

\section{REFERENCES}

[1] Hertenstein, Julie H., M. B. Platt, and R. W. Veryzer. "The Impact of Industrial Design Effectiveness on Corporate Financial Performance*." Journal of Product Innovation Management 22.1(2005):3-21.

[2] Tjalve, E. "A Short Course in Industrial Design." Journal of Clinical Pathology 44.12(1979): 1039.

[3] El-Haggar, Dr. Salah M. "Introduction - Sustainable Industrial Design and Waste Management." Sustainable Industrial Design \& Waste Management (2007):xiii-xvii.

[4] El-Haggar, Dr. Salah M. "Introduction - Sustainable Industrial Design and Waste Management." Sustainable Industrial Design \& Waste Management (2007):xiii-xvii.

[5] Tovey M. Drawing and CAD in industrial design[J]. Int.j.design Studies, 1989, 10(89):24-39.

[6] Yang, Ming Ying, M. You, and F. C. Chen. "Competencies and qualifications for industrial design jobs: implications for design practice, education, and student career guidance." Design Studies 26.2(2005):155-189.

[7] Hui, K. C., and Y. Li. "A feature-based shape blending technique for industrial design." Computer-Aided Design 30.10(1998):823-834.

[8] Bakker, C. A. "Environmental Information for Industrial Designers." Industrial Design Engineering (1995).

[9] Brown J P. A History of Industrial Design (Book)[J]. Library Journal, 1983.

[10] Ramirez, Mariano. "Sustainability in the education of industrial designers: the case for Australia." International Journal of Sustainability in Higher Education 7.2(2006):189-202(14).

[11] Roberge, D. M., Gottsponer, M., Eyholzer, M., \& Kockmann, N. (2009). Industrial design, scale-up, and use of microreactors. Chimica Oggi, 27, 8-11. 
[12] Schiele, W. L., Krüger, T., Just, K. M., \& Kirsch, F. H. (1990). A gridless router for industrial design rules. Design Automation
Conference (pp.626-631). IEEE. 